\title{
DRUG UTILISATION STUDY OF CARDIAC EMERGENCY PATIENTS IN A TERTIARY CARE HOSPITAL
}

\author{
Abdul Hannan'1, Shyamal Sinha², Pravin Jamadar ${ }^{3}$ \\ ${ }_{1}^{1}$ Assistant Professor, Department of Pharmacology, Grant Government Medical College, Mumbai. \\ ${ }^{2}$ Assistant Professor, Department of Pharmacology, Grant Government Medical College, Mumbai. \\ ${ }^{3}$ Resident, Department of Pharmacology, Grant Government Medical College, Mumbai.
}

\section{ABSTRACT}

\section{BACKGROUND}

Drug utilisation research and pharmacoepidemiology may provide insights into the pattern, quality, determinants and outcomes of use of drugs. Monitoring of prescription and drug utilisation studies could identify the associated problems and provide feedback to the prescriber so as to create awareness about the irrational use of drugs.

The objective of present study is to focus on the trends in the drug utilisation in most frequently treated cardiovascular emergencies. This information is not disease specific but reflects overall rates and illustrates trends in utilisation of drug classes and individual drugs in the treatment of cardiovascular emergencies.

\section{MATERIALS AND METHODS}

The present study was a retrospective, observational drug utilisation study to evaluate the pattern of prescriptions of drugs used in patients with cardiovascular emergencies coming to emergency unit of a tertiary health care hospital. Strengthening the Reporting of Observational Studies in Epidemiology (STROBE) guidelines were used in preparation of protocol. The following data were collected: patient demographic details, cardiovascular emergency, diagnosis of the patient, prescription details, number of drugs/prescription, percentage of drugs prescribed by generic name, percentage of drugs prescribed from essential drug list.

\section{RESULTS}

Out of 600 patients, $580(96.7 \%)$ had Ischaemic heart disease (IHD) and $20(3.3 \%)$ patients had arrhythmias. The most common associated comorbidity was hypertension (64.7\%) and the next most common associated comorbidity was diabetes mellitus (15.8\%). The top three prescribed cardiovascular drugs were Glyceryl trinitrate (96.67\%), Metoprolol (96.67\%), and Aspirin (96.67\%). In the remaining drug classes, relatively high utilisation was seen in Enalapril (93.33\%), Atorvastatin (80.00\%), Clopidogrel (76.67\%). Majority of patients were prescribed 8 drugs $(22.17 \%)$, followed by 9 drugs per encounter (15.83\%). Average number of drugs per prescription found to be around 9. Percentage of drugs prescribed by generic name was around $17.91 \%$. Percentage of drugs actually dispensed from the hospital drug store was $75.65 \%$. The percentage utilisation of scheduled drugs from the national essential drug list was $95.31 \%$.

\section{CONCLUSION}

The extent of polypharmacy was high in the present study. Majority of the patients received drug therapy as per WHO recommendations.

\section{KEYWORDS}

Drug Utilisation Study.

HOW TO CITE THIS ARTICLE: Hannan A, Sinha S, Jamadar P. Drug utilisation study of cardiac emergency patients in a tertiary care hospital. J. Evolution Med. Dent. Sci. 2017;6(27):2217-2224, DOI: 10.14260/Jemds/2017/479

\section{BACKGROUND}

The aim of this study is to evaluate the drug utilisation pattern among cardiovascular emergency patients attending emergency ward of our tertiary care teaching hospital, so that such information would help in improving the quality of care provided.

\section{Objectives/Primary}

To identify drug prescribing pattern among newly diagnosed cardiovascular emergency patients attending emergency ward of our tertiary care teaching hospital, using WHO drug use indicators.

Financial or Other, Competing Interest: None.

Submission 21-01-2017, Peer Review 10-02-2017,

Acceptance 16-02-2017, Published 01-04-2017.

Corresponding Author:

Dr. Abdul Hannan,

Assistant Professor,

Department of Pharmacology,

Grant Government Medical College, Mumbai.

E-mail: diabetes77@gmail.com

DOI: $10.14260 /$ jemds $/ 2017 / 479$

\section{Secondary}

1. To observe cardiovascular emergencies most frequently treated.

2. To observe the demographic pattern of patients with cardiovascular emergencies.

3. To observe outcome of each patient of cardiovascular emergency.

The present study was carried out in the Department of Pharmacology in collaboration with Departments of Cardiology (ICCU) in a tertiary care setup.

\section{MATERIALS AND METHODS Study Design}

It was a retrospective, observational drug utilisation study to evaluate the pattern of prescriptions of drugs used in patients with cardiovascular emergencies coming to emergency unit of a tertiary health care hospital.

Strengthening the Reporting of Observational Studies in Epidemiology (STROBE) guidelines were used in preparation of protocol. ${ }^{1}$ 


\section{Ethical Considerations}

The Study was conducted after obtaining permission from the Institutional Ethics Committee (IEC), which was DCGI Approved and registered.

All the data collected as a part of this study was kept strictly confidential and used for the purpose of this study only.

Steps taken by us to maintain Confidentiality were-

1. Identification of patients by the hospital number only and not by name.

2. Case records to be accessed by the principal investigator only.

3. Patient details not to be divulged to any party.

\section{Selection Criteria of Patients Inclusion Criteria}

Patients coming to the emergency department of tertiary care teaching hospital who are diagnosed with cardiovascular condition will be included in the study.

\section{Exclusion Criteria}

1. When diagnosis was not certain.

2. Patients with multiple diseases like stroke, structural heart diseases, liver failure and renal failure.

3. Pregnant/lactating females and children less than 18 years.

4. Patients who refuse to give informed consent.

\section{Sample Size}

A total of 600 prescriptions were analysed and diagnosed to have cardiovascular emergencies. The sample size was selected as per the WHO recommendations on conducting Drug Utilisation Studies (DUS). ${ }^{2}$

\section{Study Procedure}

The data of patients admitted with cardiovascular emergencies during the period 1st January 2014 to 31st June 2014 was collected from the ICCU ward and was recorded in a structured case record form as per Annexure 1. The sampling frame was fixed as six prescriptions per day, five days a week, during the given sampling period. The six prescriptions were selected as follows.

On day 1, all six prescriptions were chosen from the beginning of the day, on day 2 six prescriptions were chosen from the middle of the day and on day 3 , six prescriptions were chosen from the end of the day and so on. This method of selection was undertaken to ensure the randomness of the sample and avoid any selection bias.

\section{The following Data were collected}

1. Patient demographic details like patient's initial, age, gender, address, occupation, etc.

2. Patient having cardiovascular emergency with other comorbidities will be collected.

3. Diagnosis of the patient.

4. Prescription details like date, number of drugs, names of individual drugs, dosing schedule and duration of treatment.

5. Number of drugs/prescription.

6. Percentage of drugs prescribed by generic name.

7. Percentage of drugs prescribed from essential drug list.

\section{Data Analysis}

Data Analysed under following Headings-

1. Common cardiovascular emergencies treated.

2. Sex distribution of patient population.

3. Demographic characteristics of patients.

4. Associated comorbidities with cardiovascular emergencies.

5. Outcome of the treatment.

6. Average number of drugs per encounter.

7. Total number of drugs per encounter.

8. Prescribing frequency of drugs.

9. Prescribed Daily Dose.

10. Percentage of drug prescribed by generic name.

11. Percentage of drug prescribed from essential drug list.

\section{Statistical Analysis}

Descriptive and inferential statistical analysis has been carried out in the present study. Results on categorical measurements are presented in Number (\%).

\section{Statistical software:}

The Statistical software namely SAS 9.2, SPSS 15.0, Stata 10.1, MedCalc 9.0.1, Systat 12.0 and R environment ver. 2.11.1 were used for the analysis of the data. Microsoft word and Excel have been used to generate graphs, tables, etc.

Data collection began from 1 1 st January 2014 to 31st June 2014 involving 600 patients $(n=600)$ who were diagnosed with cardiovascular emergencies.

\section{Common Cardiovascular Emergencies Treated}

\begin{tabular}{|c|c|c|c|}
\hline $\begin{array}{r}\text { Sl. } \\
\text { No. }\end{array}$ & $\begin{array}{c}\text { Cardiovascular } \\
\text { Emergencies }\end{array}$ & $\begin{array}{c}\text { Number } \\
\text { of Patients }\end{array}$ & $\%$ \\
\hline 1. & Ischaemic heart disease & 580 & $96.7 \%$ \\
\hline & Myocardial infarction & 360 & $60.0 \%$ \\
\cline { 2 - 4 } & Angina pectoris & 220 & $36.7 \%$ \\
\hline 2. & Arrhythmias & 20 & $3.3 \%$ \\
\hline \multicolumn{3}{|c|}{ Table 1. The Common Cardiovascular Emergencies } \\
\hline
\end{tabular}

The table number 1 shows that, out of 600 patients, 580 (96.7\%) had Ischaemic heart disease (IHD) and 20 (3.3\%) patients had arrhythmias.

We further classified Ischaemic heart disease (IHD) into two groups: Myocardial infarction (MI) and Angina pectoris. In our study, $360(60 \%)$ patients had myocardial infarction and $220(36.7 \%)$ patients had angina pectoris.

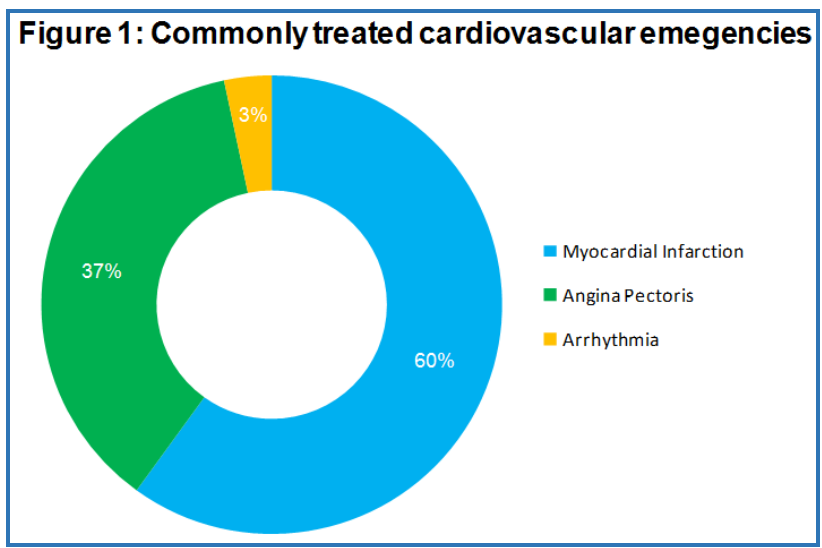


Gender Wise Distribution of Disease

\begin{tabular}{|c|c|c|c|}
\hline \multirow{2}{*}{$\begin{array}{c}\text { Cardiovascular } \\
\text { Emergencies }\end{array}$} & \multirow{2}{*}{ Total } & \multicolumn{2}{|c|}{ Gender } \\
\hline & & Male & Female \\
\hline Myocardial Infarction & 360 & $245(68.1 \%)$ & $115(31.9 \%)$ \\
\hline Angina Pectoris & 220 & $148(67.3 \%)$ & $72(32.7 \%)$ \\
\hline Arrhythmias & 20 & $14(70 \%)$ & $6(30 \%)$ \\
\hline Total & 600 & $407(67.8 \%)$ & $193(32.2 \%)$ \\
\hline
\end{tabular}

The table number 2 shows that in our study out of 600 patients, $407(67.8 \%)$ were male and 193 (32.2\%) were female.

In myocardial infarction group, 245 (68.1\%) were male and $115(31.9 \%)$ were female. In angina pectoris group, 148 $(67.3 \%)$ were male and $72(32.7 \%)$ were female. In arrhythmia group, 14 (70\%) were male and 6 (30\%) were female.

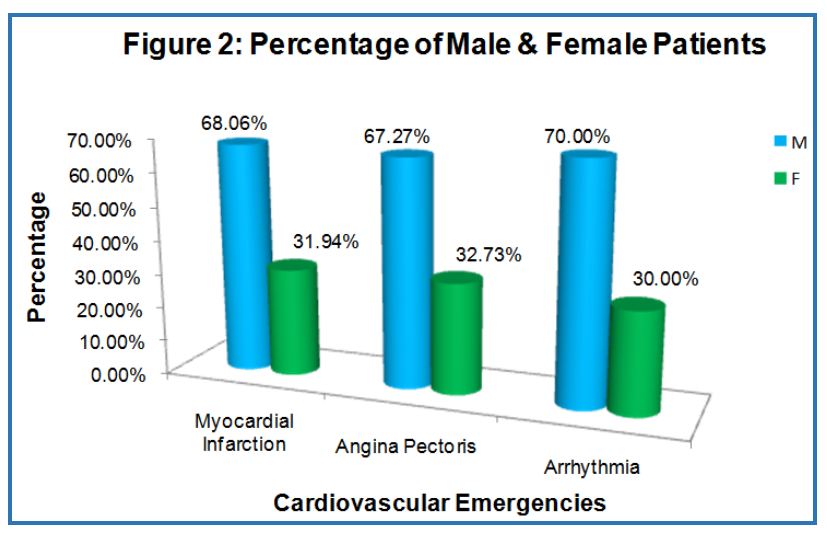

Demographic Characteristics of Cardiovascular Emergency Patients

\begin{tabular}{|c|c|c|c|}
\hline \multirow{2}{*}{ Age Groups } & \multirow{2}{*}{ Total } & \multicolumn{2}{|c|}{ Gender } \\
\cline { 3 - 4 } & & Male & Female \\
\hline $31-40$ & 6 & $6(100 \%)$ & $0(0 \%)$ \\
\hline $41-50$ & 50 & $35(70 \%)$ & $15(30 \%)$ \\
\hline $51-60$ & 180 & $138(76.67 \%)$ & $42(23.33 \%)$ \\
\hline $61-70$ & 270 & $170(62.96 \%)$ & $100(37.04 \%)$ \\
\hline $71-80$ & 80 & $48(60 \%)$ & $32(40 \%)$ \\
\hline $81-90$ & 12 & $8(66.7 \%)$ & $4(33.3 \%)$ \\
\hline $91-100$ & 2 & $2(100 \%)$ & $0(0 \%)$ \\
\hline Total & $\mathbf{6 0 0}$ & $\mathbf{4 0 7}(67.83 \%)$ & $\mathbf{1 9 3}(32.17 \%)$ \\
\hline \multicolumn{4}{|c}{ Table 3. Demographic Characteristics of Disease } \\
\hline
\end{tabular}

The table number 3 shows that the incidence of cardiovascular emergencies in our study was highest in the age group of 61-70 years. Out of 600 patients, 270 (45\%) belonged to 61-70 years age group.

The incidence of cardiovascular emergencies was less in females between age group 31-60 years (29.53\%) than between the age group 61-100 years (70.47\%).

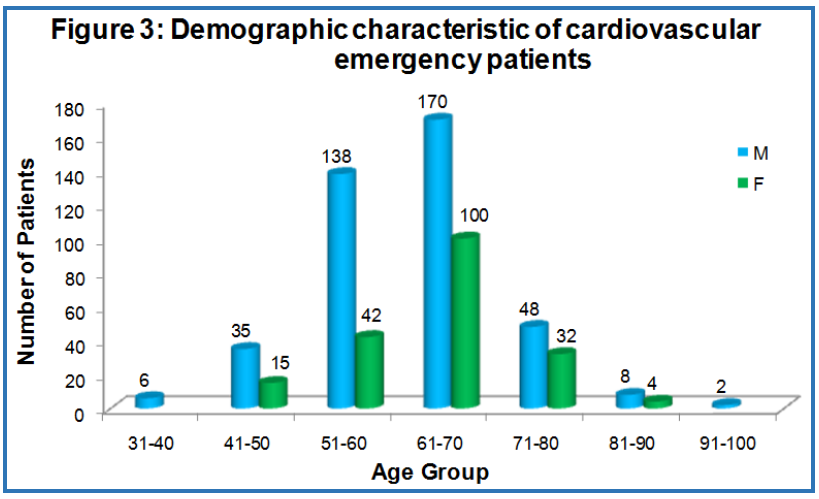

Associated Comorbid Conditions with Cardiovascular Emergencies

\begin{tabular}{|c|c|c|}
\hline Comorbidities & $\begin{array}{c}\text { Number } \\
\text { of Patients }\end{array}$ & $\%$ \\
\hline Hypertension (HTN) & 388 & $64.7 \%$ \\
\hline Diabetes Mellitus (DM) & 95 & $15.8 \%$ \\
\hline $\begin{array}{c}\text { Previous History of } \\
\text { Ischaemic Heart Disease (IHD) }\end{array}$ & 82 & $13.7 \%$ \\
\hline $\begin{array}{c}\text { Congestive Cardiac } \\
\text { Failure (CCF) }\end{array}$ & 18 & $3.0 \%$ \\
\hline $\begin{array}{l}\text { Transient Ischaemic } \\
\text { Attack (TIA) }\end{array}$ & 15 & $2.5 \%$ \\
\hline Bronchial Asthma & 2 & $0.3 \%$ \\
\hline Total & 600 & $100 \%$ \\
\hline
\end{tabular}

The table number 4 shows that in our study the most common associated comorbidity was hypertension (64.7\%) and the next most common associated comorbidity was diabetes mellitus (15.8\%).

It also shows the incidence of other associated diseases like previous history of ischaemic heart disease (13.7\%), congestive cardiac failure (3\%), transient ischaemic attack $(2.5 \%)$ and bronchial asthma $(0.3 \%)$.

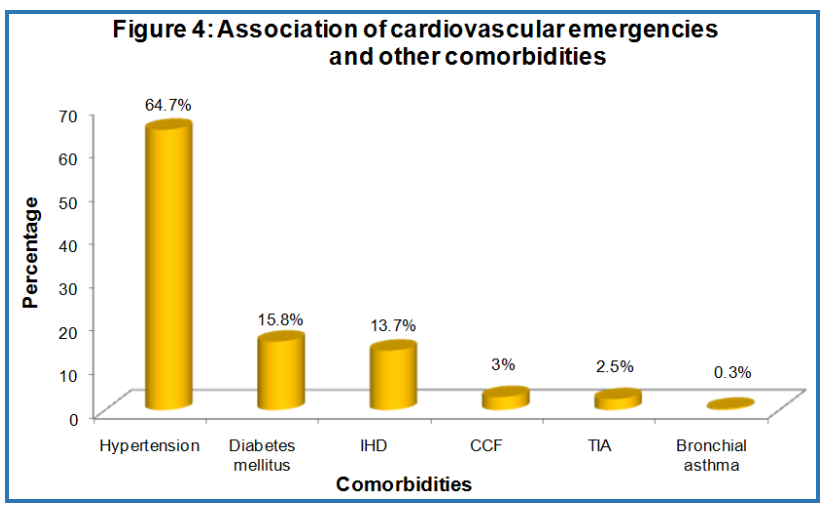

Outcome of Treatment of Patients with Cardiovascular Emergencies

\begin{tabular}{|c|c|c|c|c|}
\hline $\begin{array}{c}\text { Cardiovascular } \\
\text { Emergencies }\end{array}$ & \multirow{2}{*}{ Total } & \multicolumn{3}{|c|}{ Outcome } \\
\cline { 3 - 5 } $\begin{array}{c}\text { Myocardial } \\
\text { Infarction }\end{array}$ & 360 & $334(92.8 \%)$ & $10(2.8 \%)$ & $16(4.4 \%)$ \\
\hline $\begin{array}{c}\text { Angina } \\
\text { Pectoris }\end{array}$ & 220 & $202(91.8 \%)$ & $3(1.4 \%)$ & $15(6.8 \%)$ \\
\hline Arrhythmias & 20 & $16(80 \%)$ & $0(0 \%)$ & $4(20 \%)$ \\
\hline Total & $\mathbf{6 0 0}$ & $\mathbf{5 5 2}(\mathbf{9 2} \%)$ & $\mathbf{1 3}(2.2 \%)$ & $\mathbf{3 5}(\mathbf{5 . 8} \%)$ \\
\hline \multicolumn{6}{|c}{ Table 5. Treatment Outcome } \\
\hline
\end{tabular}


Table number 5 shows that out of 600 patients, 552 (92\%) were discharged from the hospital after treatment. Death was observed only in $13(2.2 \%)$ patients and 35 (5.8\%) patients left the hospital against medical advice.

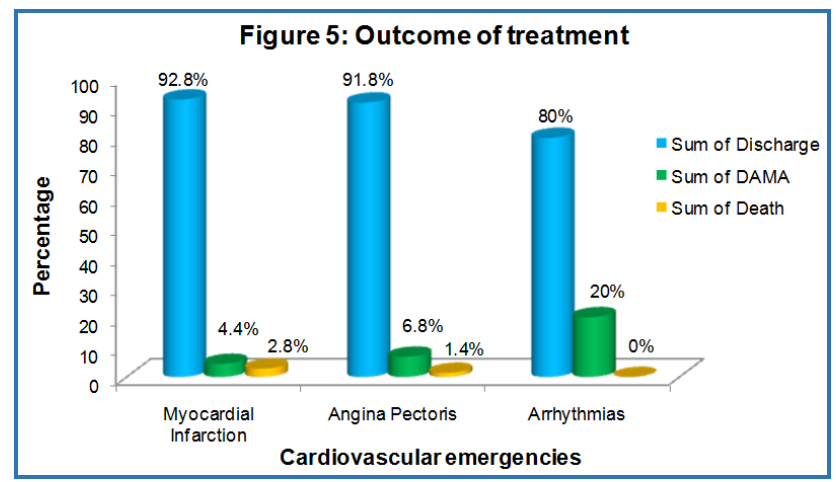

Utilisation Pattern of Drugs in Patients with Cardiovascular Emergencies

\begin{tabular}{|c|c|c|c|}
\hline $\begin{array}{l}\text { Drug } \\
\text { Class }\end{array}$ & Drug & $\begin{array}{c}\text { No. of } \\
\text { Encounters }\end{array}$ & $\%$ \\
\hline Nitrates & $\begin{array}{c}\text { Glyceryl } \\
\text { Trinitrate }\end{array}$ & 580 & $96.67 \%$ \\
\hline$\beta$ Blocker & Metoprolol & 580 & $96.67 \%$ \\
\hline ACE Inhibitor & Enalapril & 560 & $93.33 \%$ \\
\hline \multirow{2}{*}{ Antiplatelet } & Aspirin & 580 & $96.67 \%$ \\
\hline & Clopidogrel & 460 & $76.67 \%$ \\
\hline Anticoagulant & Heparin & 395 & $65.83 \%$ \\
\hline Fibrinolytic & Streptokinase & 255 & $42.50 \%$ \\
\hline Hypolipidaemic & Atorvastatin & 480 & $80.00 \%$ \\
\hline $\begin{array}{l}\text { Calcium } \\
\text { Channel } \\
\text { Blocker }\end{array}$ & Diltiazem & 20 & $3.33 \%$ \\
\hline $\begin{array}{c}\text { Cardiac } \\
\text { Glycoside }\end{array}$ & Digoxin & 18 & $3.00 \%$ \\
\hline Anti-Arrhythmic & Amiodarone & 30 & $5.00 \%$ \\
\hline Glucocorticoids & Hydrocortisone & 255 & $42.50 \%$ \\
\hline \multirow{2}{*}{ Antacids } & Ranitidine & 565 & $94.17 \%$ \\
\hline & Pantoprazole & 262 & $43.67 \%$ \\
\hline Laxative & $\begin{array}{c}\text { Magnesium } \\
\text { Hydroxide } \\
\text { \& Liquid } \\
\text { Paraffin }\end{array}$ & 260 & $43.33 \%$ \\
\hline $\begin{array}{l}\text { Sedative- } \\
\text { Hypnotic }\end{array}$ & Diazepam & 245 & $40.83 \%$ \\
\hline Tabl & Orugs resct & $\begin{array}{l}\text { d in Patients } \\
\text { nergencies }\end{array}$ & \\
\hline
\end{tabular}

Table number 6 shows that the top three prescribed cardiovascular drugs were Glyceryl trinitrate (96.67\%), Metoprolol (96.67\%), and Aspirin (96.67\%). In the remaining drug classes, relatively high utilisation was seen in Enalapril (93.33\%), Atorvastatin (80.00\%), Clopidogrel (76.67\%).

Total Number of Drugs per Encounter

\begin{tabular}{|c|c|c|}
\hline $\begin{array}{c}\text { Number } \\
\text { of Drugs }\end{array}$ & $\begin{array}{c}\text { Number } \\
\text { of Encounters }\end{array}$ & $\mathbf{\%}$ \\
\hline 3 & 13 & $2.17 \%$ \\
\hline 4 & 07 & $1.17 \%$ \\
\hline 6 & 19 & $3.17 \%$ \\
\hline
\end{tabular}

\begin{tabular}{|c|c|c|}
\hline 7 & 68 & $11.33 \%$ \\
\hline 8 & 133 & $22.17 \%$ \\
\hline 9 & 95 & $15.83 \%$ \\
\hline 10 & 77 & $12.83 \%$ \\
\hline 11 & 91 & $15.17 \%$ \\
\hline 12 & 68 & $11.33 \%$ \\
\hline 13 & 24 & $4.0 \%$ \\
\hline 14 & 05 & $0.83 \%$ \\
\hline \multicolumn{2}{|c|}{ Table 7. Total Number of Drugs per Encounter } \\
\hline
\end{tabular}

Table number 7 shows that majority of patients were prescribed 8 drugs (22.17\%), followed by 9 drugs per encounter (15.83\%).

Analysis of Prescription Pattern According to WHO Drug use Indicators

\begin{tabular}{|c|c|c|}
\hline $\begin{array}{l}\text { Sl. } \\
\text { No. }\end{array}$ & $\begin{array}{l}\text { Drug use } \\
\text { Indicators }\end{array}$ & Results \\
\hline 1. & $\begin{array}{l}\text { Total Number of Different } \\
\text { Drugs Prescribed }\end{array}$ & 5545 \\
\hline 2. & $\begin{array}{l}\text { Total Number } \\
\text { of Encounters }\end{array}$ & 600 \\
\hline 3. & $\begin{array}{l}\text { Average Number of } \\
\text { Drugs per Encounter }\end{array}$ & 9.24 \\
\hline 4. & $\begin{array}{c}\text { Percentage of Drugs } \\
\text { Prescribed by Generic Name }\end{array}$ & $\begin{array}{c}17.91 \% \\
(993 / 5545) \\
\end{array}$ \\
\hline 5. & $\begin{array}{l}\text { Percentage of Drugs Actually } \\
\text { Dispensed from the } \\
\text { Hospital Drug Store }\end{array}$ & $\begin{array}{c}75.65 \% \\
(4195 / 5545)\end{array}$ \\
\hline 6. & $\begin{array}{c}\text { Percentage Utilisation } \\
\text { of Scheduled } \\
\text { Drugs from the NLEM } 2011\end{array}$ & $\begin{array}{c}95.31 \% \\
(5285 / 5545)\end{array}$ \\
\hline \multicolumn{3}{|c|}{$\begin{array}{l}\text { Table 8. Assessment of the Prescription } \\
\text { Pattern as per Various Drug use Indicators }\end{array}$} \\
\hline
\end{tabular}

Table number 8 shows that six hundred prescriptions analysed contained a total of 5545 drugs. There was no prescription with more than 14 drugs. Average number of drugs per prescription found to be around 9. Percentage of drugs prescribed by generic name was around $17.91 \%$. Percentage of drugs actually dispensed from the hospital drug store was $75.65 \%$. The percentage utilisation of scheduled drugs from the national essential drug list was 95.31\%.

\section{Percentage of Drugs Prescribed by Generic Name}

In our study out of 5545 drugs, 993 drugs were prescribed by generic name and 4552 drugs were prescribed by brand name. So, $17.91 \%$ drugs were prescribed by generic name and $82.09 \%$ drugs were prescribed by brand name. (Figure 8).

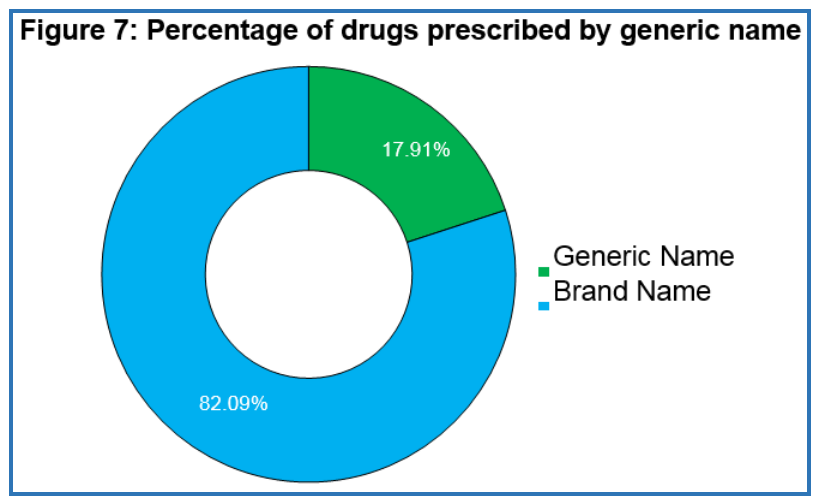




\section{Percentage of Drugs Prescribed from Essential Medicine} List

Out of 5545 drugs used, 5285 drugs were prescribed from National List of Essential Medicines (NLEM) 2011. So, 95.31\% drugs were prescribed from NLEM 2011. (Figure 8).

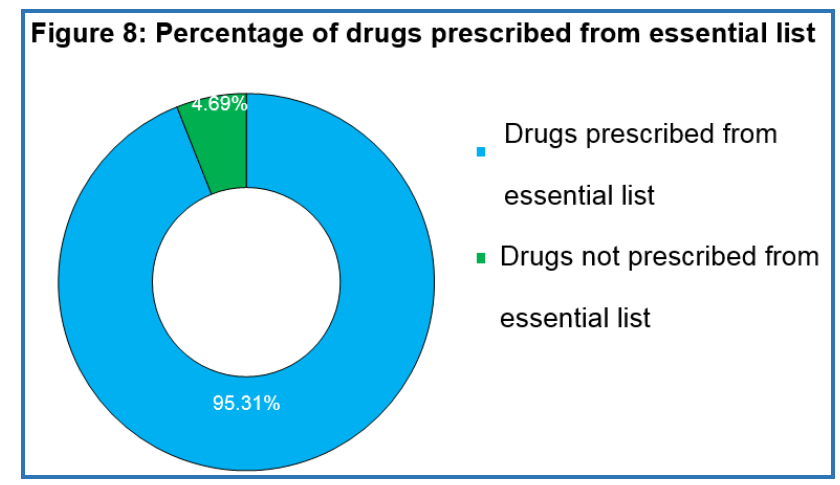

PDD and DDD Calculation

\begin{tabular}{|c|c|c|c|c|c|}
\hline $\begin{array}{c}\text { Sl. } \\
\text { No. }\end{array}$ & $\begin{array}{c}\text { ATC } \\
\text { Code }\end{array}$ & Drug & $\begin{array}{c}\text { PDD* } \\
\text { (Grams) }\end{array}$ & $\begin{array}{c}\text { DDD* } \\
\text { (Grams) }\end{array}$ & $\begin{array}{c}\text { PDD/ } \\
\text { DDD }\end{array}$ \\
\hline 1. & C01DA02 & $\begin{array}{c}\text { Glyceryl } \\
\text { Trinitrate }\end{array}$ & 0.025 & - & - \\
\hline 2. & C07AB02 & Metoprolol & 0.025 & 0.15 & 0.16 \\
\hline 3. & C09AA02 & Enalapril & 0.005 & 0.01 & 0.5 \\
\hline 4. & B01AC06 & Aspirin & 1 tablet & 1 tablet & 1 \\
\hline 5. & B01AC04 & Clopidogrel & 0.15 & 0.075 & 2 \\
\hline 6. & B01AB01 & Heparin & $15 \mathrm{IU}$ & $10 \mathrm{IU}$ & $1.5 \mathrm{IU}$ \\
\hline 7. & B01AD01 & Streptokinase & $1.5 \mathrm{MU}$ & $1.5 \mathrm{MU}$ & 1 \\
\hline 8. & C10AA05 & Atorvastatin & 0.04 & 0.02 & 2 \\
\hline 9. & C08DB01 & Diltiazem & 0.09 & 0.24 & 0.75 \\
\hline 10. & C01AA05 & Digoxin & 0.00025 & 0.00025 & 1 \\
\hline 11. & C01BD01 & Amiodarone & 0.2 & 0.2 & 1 \\
\hline 12. & H02AB09 & Hydrocortisone & 0.1 & 0.03 & 3.33 \\
\hline 13. & A02BA02 & Ranitidine & 0.3 & 0.3 & 1 \\
\hline 14. & A02BC02 & Pantoprazole & 0.04 & 0.04 & 1 \\
\hline 15. & N05BA01 & Diazepam & 0.005 & 0.01 & 0.5 \\
\hline \multicolumn{5}{|c|}{ Table 9. ATC/DDD Classification, PDD Values } \\
\hline \multicolumn{7}{|c|}{ and PDD/DDD Ratio of Drugs used in } \\
\hline
\end{tabular}

*DDDs mentioned in the table are obtained from the WHO ATC/DDD website.

ATC Code- Anatomical Therapeutic Chemical Classification Code,

PDD- Prescribed Daily Dose, DDD- Daily Defined Dose.

Drug Cost Analysis

\begin{tabular}{|c|c|c|}
\hline $\begin{array}{c}\text { Sl. } \\
\text { No. }\end{array}$ & $\begin{array}{c}\text { Cost } \\
\text { Parameter }\end{array}$ & $\begin{array}{c}\text { Cost } \\
\text { Calculated }\end{array}$ \\
\hline 1. & $\begin{array}{c}\text { Total Cost of } \\
\text { Drugs Prescribed }\end{array}$ & 722719.61 INR \\
\hline 2. & $\begin{array}{c}\text { Total Number } \\
\text { of Encounters }\end{array}$ & 600 \\
\hline 3. & $\begin{array}{c}\text { Average Total } \\
\text { Cost per Encounter }\end{array}$ & $\begin{array}{c}1204.53 \text { INR } \\
(722719.61 / 600)\end{array}$ \\
\hline 4. & $\begin{array}{c}\text { Average Cost Borne } \\
\text { by the Hospital }\end{array}$ & $\begin{array}{c}932.71 \text { INR } \\
(559628.21 / 600)\end{array}$ \\
\hline 5. & $\begin{array}{c}\text { Average Cost Borne } \\
\text { by the Patient }\end{array}$ & $\begin{array}{c}271.82 \text { INR } \\
(163091.40 / 600)\end{array}$ \\
\hline \multicolumn{2}{|c|}{ Table 10. Drug Cost Parameters } \\
\hline
\end{tabular}

Table number 10 shows various drug cost parameters. The drugs prescribed in the hospital and those prescribed from outside the hospital were analysed further in terms of their cost.

Cardiovascular disease (CVD) is the most frequent cause of morbidity and mortality throughout the world. Many of these disorders present as emergencies e.g. myocardial infarction, unstable angina, arrhythmias and hypertensive crisis, the leading causes of death. CVD is the leading cause of death, and ischaemic heart disease (IHD) and stroke are the major contributors to CVD. Worldwide, $80 \%$ of deaths from CVD now occur in low- and middle-income countries. ${ }^{3}$ Thus, there is a special and urgent need for data and treatment strategies concerning CVD in low and middle income countries. It is estimated that by 2020, CVD will be the largest cause of disability and death in India. 4

Different studies on drug utilisation have revealed wide geographical differences in use of same group of drugs. Drug utilisation study addresses the relationship between the recommended therapeutic practice and actual clinical practice. Despite the advances in detection, treatment and management of acute coronary syndrome, it continues to be a significant contributor to the mortality and morbidity attributed to cardiovascular diseases, even in developing countries. Prompt and early detection of cardiovascular emergencies and immediate initiation of therapy are therefore necessary for reduction in mortality and morbidity due to cardiovascular emergencies. ${ }^{5,6}$

Drug utilisation among outpatient is frequently monitored in many countries but the studies on inpatients are rare and incomplete. Also studies of drug utilisation in myocardial infarction and hypertension are available but studies on other cardiovascular emergencies are low. So we planned the present study to focus the trends in drug utilisation in most frequently treated cardiovascular emergencies in a tertiary care centre.

\section{Study Procedure}

The present study was carried out in the Department of Pharmacology in collaboration with Departments of Cardiology (ICCU) after obtaining permission from the Institutional Ethics Committee (IEC), in a tertiary care setup. A total of 600 prescriptions were analysed and diagnosed with cardiovascular emergencies during the period 1st January 2014 to 31st June 2014. The data were collected from the ICCU ward and was recorded in a structured case record form as per Annexure 1. The sample size was selected as per the WHO recommendations on conducting Drug Utilisation Studies (DUS). ${ }^{2}$ All the data collected as a part of this study were kept strictly confidential and used for the purpose of this study only.

\section{Distribution of Cardiovascular Emergencies}

In our study, myocardial infarction $(60 \%)$ was the most common cardiovascular emergency treated (Table 1). This correlated with Heart Disease and Stroke Statistics- 2013 update, given by Alan S et $\mathrm{al}^{7}$ which indicates that myocardial infarction is the most common cause of cardiovascular morbidity and mortality. The second most common emergency was angina pectoris (36.7\%). The reasons for high incidence of these two emergencies are multifactorial. With urbanisation in developing world especially India, the 
prevalence and risk factors for IHD is increasing rapidly and majority of the global burden of IHD is now occurring in low and middle income countries like India. ${ }^{8}$

\section{Demographic Characteristic of Study Participants}

In our study, out of six hundred patients, $67.8 \%$ were male and $32.2 \%$ were female (Table 2). It means that more male patients were affected as compared to female patients. This correlates with the similar study conducted by Sheikh Mahmood Hasan in which $68 \%$ of the cases were male and $32 \%$ were female among the patients affected from cardiovascular emergencies. These results are in accordance to standard literature ${ }^{9}$ which states that oestrogen increases high density lipoprotein (HDL) and lowers low density lipoprotein (LDL), whereas the androgens have the opposite effect. In our study, $68.1 \%$ of myocardial infarction patients were male. These results are also similar in comparison to study conducted by Scott et al in which $66.3 \%$ of myocardial infarction patients were male.

In our study, incidence of cardiovascular emergencies was highest in the age group of 61-70 years. Out of 600 participants, $45 \%$ patients belonged to $61-70$ years age group (Table 3), which is in comparison to study conducted by Scott et al in which the mean age was 67 years. These results also correlate with the study conducted by Mukharjee et al in which the mean age was 63 years.

In our study, incidence of cardiovascular emergencies was less in females between age group 31-60 (29.53\%) years as compared to females between age group 61-100 years (70.47\%) (Table 3). These results are in accordance with standard literature which states that cardiovascular morbidities are less in premenopausal females as compared to postmenopausal females due to endogenous oestrogen.

\section{Associated Comorbid Conditions with Cardiovascular Emergencies}

In our study, hypertension $(64.7 \%)$ was the most common comorbidity in patients with cardiovascular emergencies (Table 4). This was followed by diabetes mellitus (15.8\%), this is in comparison to study conducted by Mukharjee et al in which hypertension was associated with $66.8 \%$ patients, followed by diabetes mellitus in $30 \%$ patients. These results are also similar to study conducted by Sheikh Mahmood Hasan in which hypertension followed by diabetes mellitus were the most common comorbidities in patients with cardiovascular emergencies. In the study conducted by Ayman El-Menyar et al, $35.5 \%$ of the patients were having hypertension and $27 \%$ patients were having diabetes mellitus as the most common comorbid conditions which is in accordance with our results.

\section{Outcome of Treatment}

In our study, we observed that outcome of the treatment was favourable for all cardiovascular emergencies. In our study, 92.8\% patients of myocardial infarction, 91.8\% patients of angina pectoris and $80 \%$ patients of arrhythmias were discharged from the hospital (Table 5). ${ }^{10,11}$ In our study, the mortality from myocardial infarction was $2.8 \%$, which is less than that reported by Jose and Gupta (22.64\%). In our study, the mortality from angina pectoris was $1.4 \%$, which is less than that reported by Pais $\mathrm{P}$ et al (3.7\%). In our study, there was no mortality from arrhythmias, which is also less than that reported by Shavadia J (6\%). Out of 600 patients, $4.4 \%$ of myocardial infarction, $6.8 \%$ of angina pectoris and $20 \%$ of patients with arrhythmias had taken discharge against medical advice (DAMA).

\section{Utilisation Pattern of Cardiovascular Drugs}

In our study, the three most common cardiovascular drugs prescribed were glyceryl trinitrate (96.67\%), metoprolol (96.67\%) and aspirin (96.67\%) as shown in Table 6. Among the remaining drug classes, relatively high utilisation was seen for enalapril (93.33\%), atorvastatin (80\%) and clopidogrel (76.67\%). These findings correlated with the standard guidelines ${ }^{12,13}$ mentioned for drug use in cardiovascular emergencies. These results are also comparable to results of studies conducted by Menon et al and Schiele et al.

In the study conducted by Menon et al, prescribing frequency of aspirin was 92\%, of heparin $83 \%$ and of clopidogrel was $42 \%$. In the study conducted by Scott et al, prescribing frequency of aspirin, hypolipidaemics and nitrates was $89 \%, 41 \%$ and $49 \%$ respectively. In study conducted by Schiele et al, prescribing frequency of aspirin, beta blocker, ACE inhibitors and statins was 91\%, 39\%, 45\% and $62 \%$ respectively.

In our study, utilisation rate of beta blocker (96.67\%) and ACE inhibitors (93.33\%) was much more than other antihypertensive drugs. This correlates with the present trends of increased use of beta blockers and ACE inhibitors in myocardial infarction and other cardiovascular emergencies to improve morbidity and mortality. According to Friedman et al, use of ACE inhibitors in myocardial infarction patients was associated with substantial reduction in mortality. In other two studies conducted by Doubeni et al and Claudia et al, the percentage of prescription of ACE inhibitors was $68 \%$ and $63 \%$ respectively.

In our study, prescribing frequency of hydrocortisone was $42.50 \%$ which is similar to fibrinolytic streptokinase. Hydrocortisone was used in every case in which streptokinase was given. Explanation given by physicians for concurrent use of hydrocortisone with streptokinase was to prevent allergic reactions due to streptokinase, but this is in contrast to the standard guidelines, 14 which states that hydrocortisone should be used only when there are signs or symptoms of allergic reaction and not for prevention of allergic reactions. So use of hydrocortisone with streptokinase is controversial.

In our study, streptokinase was prescribed in 255 (42.50\%) patients (Table 6) whereas total patients of myocardial infarction were $360(60 \%)$ as shown in Table 1. This variation may be due to the reason that streptokinase is indicated only in patients with ST segment elevated myocardial infarction. Also in patients reaching late to hospital after the onset of chest pain, streptokinase is less efficacious.

In our study, ranitidine was used in $94.17 \%$ patients with cardiovascular emergencies. This is not in accordance with standard treatment guidelines for treatment of cardiovascular conditions. Explanation assigned to use of ranitidine in this situation is to prevent stress-induced gastritis.

Out of all the drugs prescribed, five drugs were prescribed from outside the hospital. These include 
Metoprolol, Clopidogrel, Diltiazem, Amiodarone and syrup Cremaffin because of their unavailability in the hospital drug store.

\section{Analysis of Prescription Pattern According to WHO Drug Use Indicators}

The various indicators analysed were average number of drugs per prescription, percentage of drugs prescribed by their generic names, percentage of drugs prescribed and dispensed from the hospital schedule and percentage utilisation of scheduled drugs from the National Essential Drug List.

In our study, the total number of different drugs prescribed were 5545 (Table 8). The average number of drugs per prescription was 9.24, which was similar to study conducted by Shruthi Dawalji et al in which average number of drugs per prescription was 9.68 .

The percentage of drugs prescribed by their generic names in our study was $17.91 \%$ as shown in Figure 7 . This finding is higher than the similar study conducted by Shruthi Dawalji et al in which percentage of drugs prescribed by generic names was $2.33 \%$. In similar previous studies, percentage of drugs prescribed by generic names varied. In our study, it is clearly evident that majority of drugs were not prescribed by generic names which do not justify rational drug prescriptions.

In our study, percentage of drugs actually dispensed from the hospital drug store was $75.65 \%$ which is more than drugs prescribed from outside the hospital. Out of 16 drugs used, 15 drugs were prescribed from National List of Essential Medicines (NLEM) 2011 (Figure 8). So, 95.51\% drugs were prescribed from NLEM 2011 which points towards rational prescription practices. Use of drugs from the Essential Drug List should be prompted for optimal use of limited financial resources, to have acceptable safety and to satisfy the health needs of the majority of the population.

\section{ATC/DDD Classification and DUS Metrics}

All the drugs prescribed were classified according to the Anatomical Therapeutic Chemical (ATC)-Daily Defined Dose (DDD) classification. The ATC classification system divides drugs into different groups according to the organ or system on which they act and their chemical, pharmacological and therapeutic properties. The 'DDD' concept was developed to overcome the objections against the traditional units of the measurement of drug consumption and to ensure comparability between the drug utilisation studies which were carried out at different locations and at different time periods. ${ }^{15}$ It is important to remember that the DDD is the assumed average maintenance dose per day for a drug which is used for its main indication in adults. 16

The prescribed daily dose (PDD) is defined as the average dose prescribed according to a representative sample of prescriptions. When there is a substantial discrepancy between the PDD and the DDD, it is important to take this difference into consideration when evaluating and comparing drug utilisation figures.

In our study, Aspirin, Streptokinase, Digoxin, Amiodarone, Ranitidine and Pantoprazole had PDD/DDD ratio equal to 1 . Metoprolol, Enalapril, Diltiazem and Diazepam had the PDD/DDD ratios below 1 and Clopidogrel, Atorvastatin and hydrocortisone had highest PDD/DDD ratio above 1. The DDD of Glyceryl trinitrate (Parenteral route) is not available at the WHO ATC/DDD website.

When the PDD/DDD ratio is either less than or greater than 1, it may indicate that there is either under or overutilisation of drugs. Having said that, it is important to note the PDD can vary according to both the illnesses treated and national therapeutic practices. The PDDs also vary substantially between different countries, for example, PDDs are often lower in Asian than in Caucasian populations. Because of this it may seem as if there is underutilisation of a particular drug as per the PDD/DDD ratio. ${ }^{17,18}$

\section{Cost Analysis}

The average cost per prescription was 1204.53 INR. Out of which, the cost borne by the hospital was almost thrice (932.71 INR.) the cost borne by the patients (271.82 INR.) as shown in Table 10. This was because a large percentage of drugs were prescribed (75.65\%) from the hospital pharmacy. These drugs were provided free of cost to the patients thereby reducing their cost burden. Being a general hospital, most of these patients were from a low socioeconomic background, thus, providing free drugs to them helps to improve compliance. ${ }^{19,20}$

We found out that the choice of drugs was based more on their availability in the hospital pharmacy. Ideally, all the available treatment options should be presented to the patient, their pros and cons explained and then the patient should be allowed to choose the best drug even if it is not available in the hospital drug store. There were no similar studies published, with whom we could compare our cost parameters. It is important to keep in mind that expenditure on travel, and the time and money spent in consulting add to the total health care cost. In a developing country like India, cost is an important factor that determines compliance.

\section{CONCLUSION}

Majority of patients in the present study received rational therapy in accordance with WHO recommendations. The extent of polypharmacy was high in the present study indicating the need of targeted education of prescription givers.

\section{REFERENCES}

[1] Mozaffarian D, Benjamin EJ, Go AS, et al. Heart disease and stroke statistics-2015 update: a report from the American Heart Association. Circulation 2015;131(4):e29-e322.

[2] WHO. How to investigate drug use in health facilities: selected drug use indicators - EDM Research series No. 007 (WHO/DAP/93.1). 1993;3:28-30.

[3] Stouffer GA. Percutaneous Coronary Intervention (PCI): $\quad$ Practice $\quad 2016$. http://emedicine.medscape.com/article/161446overview.

[4] Neeman M. Cardiovascular diseases in India. http://www.neemanmedical.com/sites/default/files/ files/Cardiovascular\%20Diseases\%20in\%20India_0.p $\mathrm{df}$ 
[5] Levine GN, Bates ER, Blankenship JC, et al. 2011 ACCF/AHA/SCAI guideline for percutaneous coronary intervention: a report of the American College of Cardiology Foundation/American Heart Association task force on practice guidelines and the society for cardiovascular angiography and interventions. Circulation 2011;124(23):e574-e651.

[6] Qaseem A, Fihn SD, Dallas P, et al. Management of stable ischemic heart disease: summary of a clinical practice guideline from the American College of Physicians/American College of Cardiology Foundation/American Heart Association/American Association for Thoracic Surgery/Preventive Cardiovascular Nurses Association/Society of Thoracic Surgeons. Ann Intern Med 2012;157(10):735-43.

[7] Fihn SD, Gardin JM, Abrams J, et al. Guideline for the diagnosis and management of patients with stable ischemic heart disease: executive summary: a report of the American College of Cardiology Foundation/American Heart Association task force on practice guidelines, and the American College of Physicians, American Association for Thoracic Surgery, Preventive Cardiovascular Nurses Association, Society for Cardiovascular Angiography and Interventions and Society of Thoracic Surgeons. J Am Coll Cardiol 2012;60(24):e44-e164.

[8] Perk J, De Backer G, Gohlke H, et al. European Guidelines on cardiovascular disease prevention in clinical practice (version 2012). The fifth joint task force of the European Society of Cardiology and other societies on Cardiovascular Disease Prevention in Clinical Practice (constituted by representatives of nine societies and by invited experts). Eur J Prev Cardiol 2012;19(4):585-667.

[9] Montalescot G, Sechtem U, Achenbach S, et al. For The Task Force on the management of stable coronary artery disease of the European Society of Cardiology. 2013 ESC guidelines on the management of stable coronary artery disease. Eur Heart J 2013;34(38):2949-3003.
[10] Davidsen F, Haghfelt T, Gram LF, et al. Adverse drug reactions and drug non-compliance as primary causes of admission to a cardiology department. Eur J Clin Pharmacol 1988;34(1):83-6.

[11] Bordet R, Gautier S, Le Louet H, et al. Analysis of the direct cost of adverse drug reactions in hospitalised patients. Eur J Clin Pharmacol 2001;56(12):935-41.

[12] Kinnaird TD, Stabile E, Mintz GS, et al. Incidence, predictors and prognostic implications of bleeding and blood transfusion following percutaneous coronary interventions. Am J Cardiol 2003;92(8):9305.

[13] Lauer MA, Karweit JA, Cascade EF, et al. Practice patterns and outcomes of percutaneous coronary interventions in the United States: 1995 to 1997. Am J Cardiol 2002;89(8):924-9.

[14] Williamson J, Chopin JM. Adverse reactions to prescribed drugs in the elderly: a multicentre investigation. Age Ageing 1980;9(2):73-80.

[15] Introduction to Drug Utilization Research, WHO International Working Group for Drug Statistics Methodology, WHO Collaborating Centre for Drug Statistics Methodology, WHO, 2003.

[16] Brahma D, Marak M, Wahlang J, et al. Rational use of drugs and irrational drug combinations. The Internet Journal of Pharmacology 2012;10(1).

[17] WHO. How to investigate drug use in health facilities selected drug use indicators. Geneva Action Programme on Essential Drugs, World Health Organization. (WHO/DAP/93.1), 1993.

[18] World Health Organization. Introduction to Drug Utilization Research: Oslo, 2003. http://www.who.int/medicines/areas/quality_safety /safety_efficacy/drug_utilization_research.pdf?ua=1

[19] Maiti R. Postgraduate topics in pharmacology. 1st edn. Hyderabad: Paras Medical Books 2013. World Health Organization.

[20] WHO. Model lists of essential medicines. 19th List. 2015.

http://www.who.int/medicines/publications/essenti almedicines/EML_2015_FINAL_amended_NOV2015.p df?ua $=1$ 